\title{
How to Develop a Learning Model with a Spiritual Method to Midwifery Diploma IV Students
}

\author{
Hasnerita, Suyitno Muslim, Atwi Suparman
}

\begin{abstract}
Pregnancy and childbirth are chain reactions that cannot be separated in the lives of normal women. Because they have prepared thoroughly starting from the physical, mind, and motivation and have had the awareness to return to the concept of giving birth naturally and paying attention to all aspects of the human body holistically. The aim of this study is to create a midwifery learning model with a spiritual approach for Midwifery Diploma IV students so that the process for pregnancy and childbirth natural. This research method is a development research known as $R \& D$ (Research and Development) developed by Borg and Gall with a qualitative approach. Formative evaluations consisted of expert reviews, one to one, small groups, and field trials. This research was conducted at the Ministry of Health Polytechnic III, the trial respondents were 29 midwifery D IV students in the Seventh Semester. Data was collected through interviews, questionnaires, and field observations. Data analysis using descriptive methods. The results of the study can be concluded that the value of product quality achieved on average starts from individual trials at the level of 4.30 or $86.11 \%$, while the small group trials at the level of 4.34 or $87 \%$ and field trials are at the level at 4.45 or $89.14 \%$ with the overall average being at 4.37 or $87.42 \%$ in the excellent category. The conclusions of the spiritual midwifery learning model have been developed, it has been proven to be able to make students motivated, easy to understand, very interesting to learn because it includes exercises, examples, films and success stories from clients to clarify concepts and bring students to the real world and are easy to apply.
\end{abstract}

Index Terms: Research Development, Spiritual Approach, Midwifery Learning Model

\section{INTRODUCTION}

The increasingly rapid development of health technology, especially midwifery has renewed the role of midwives in midwifery practice. Midwives as professions must follow developments and changes in globalization. The era of globalization requires the availability of professional human resources in providing services to the community. Professionalism is closely related to the competencies that

Revised Manuscript Received on September 22, 2019.

Hasnerita, Post Graduated Departmen of Educational Technology Universitas Negeri Jakarta. Rawamangun muka street, Rawamangun Pulogadung, East Jakarta 13220, Indonesia., Hanerita_tp13s3@mahasiswa.unj.ac.id

Suyitno Muslim, Profesor at Universitas Negeri Jakarta. Rawamangun Muka street, Rawamangun Pulogadung, East Jakarta 13220, Indonesia

Atwi Suparman, Profesor at Universitas Terbuka Jakarta. Jalan Cabe Raya, Pondok Cabe Pamulang, Tangerang Selatan 15418, Banten Indonesia must be possessed by a profession.

The development of the roles and functions and competencies of midwives are prepared through education, midwifery practices have long been known as art and science. Teaching innovations that aim to facilitate and explore students are fundamental, complex and that are important for effective practice and midwifery skills. Through art and humanities exploration, students are encouraged to engage with concepts such as caring, empathy, maternal suffering, illness, love, attachment, health, and disease.

The efforts made by the Royal College of Midwives have put normal births back on top of the agenda of 'fighting for normality' through the 'Normal Birth Campaign'. Professional midwives are experts who are skilled in supporting and maximizing normal births and their skills must be promoted and valued. The role of midwives is an integral part of the care model, which promotes normality. Maternity services can improve midwifery skills and autonomous practice by providing appropriate practice arrangements (Midwives, Mey 2004).

The Empathy of midwives and spiritual care can play a key role in creating positive birth and nurturing experiences. Further research on the role of empathy and spiritual care in improving midwifery practices and birth control, birth as sacred in the midwifery curriculum (Moloney \& Gair, 2015)

Labor as a spiritually meaningful event experienced by the body, although the developing literature and the development of guidelines imposing midwives to provide spiritual care feel spiritual experiences are not welcomed. There is a need to revisit contemporary approaches to spiritual care in midwifery so that something significant becomes lost in policy rhetoric (Crowther \& Hall, 2015)

Spiritual care has a higher spiritual perception, For this reason spiritual care subjects are included in the nursing and midwifery education curriculum and training for midwives who have worked (Kostak \& Celikkalp, 2016), (Hall, 2016)

The first international study that perceived spiritual care competency was developed in undergraduate nursing and midwifery students and that students' perceptions of spirituality and spirituality personally contributed to development. (Ross et al., 2018), Research (Josephine, Donia, \& Baldacchino, 2014) Learning units taught about spiritual care in nursing /midwifery education before or after enrollment can

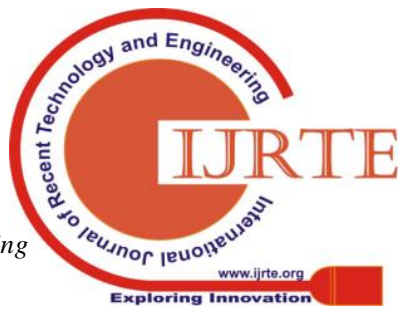


contribute to the acquisition of competencies in spiritual care.

Apart from the use of traditional teaching methods, such as lessons and seminars, other methods are used continuously in all study units, for example, self reflection exercises, case studies and small group discussions to improve learning. Recommendations are proposed to review the contents of this study unit and to introduce other teaching methods for effective learning (Baldacchino, 2008).

Based on the above research, there has been no research on the development of midwifery concept learning curricula with a spiritual approach to the midwifery Diploma IV in Indonesia.

Research Objectives: Creating a midwifery learning model with a spiritual approach that is suitable for midwifery Diploma IV students so that the process of pregnancy and childbirth is natural.

\section{LITERATURE REVIEW}

Models an abstraction that can be used to help understand something that cannot be seen or experienced directly. According to the (Richey \& Klein, 2014) model is a representation of reality which is presented with a degree of structure and sequence. There are models that are procedural in nature, namely describing how to do tasks, or are conceptual, namely verbal descriptions of reality by presenting relevant components and definitions, with the support of data.

Development of a learning model is a complex process, when appropriately applied, promotes creativity during development and produces effective and interesting instructions for students. The instructional development model conveys guiding principles for analyzing, producing and revising the learning environment (Branch, 2002).

Understanding of the theory and design of learning is the theory that offers help to learn and develop. The types of learning development may include cognitive, emotional, social, physical, and spiritual (Reigeluth, 1999).

Developing learning models it is very important to identify learning tasks that are directed and selected with assessment methods to measure what they are expect to achieve (Molenda \& Januszewski, 2008)

Dick, Carey, and Carey argue that the learning process is a system, aimed at facilitating learning. The components of the learning system are students, instructors, learning materials, and learning environments. All components are mutually integrated to achieve the expected goals. To ensure that the learning process is as expected, an assessment is carried out. In his explanation Dick, Carey, and (Walter Dick, 2015),

Propose a view that has similarities with Dick, Carey, and Carey, that the model of learning development is a system in developing an education, the meaning expressed is: "Is a system of procedures for developing Curricula education and training is a consistent and reliable fashion. The general system concept is characterized as being systematic, systematic, responsive, interdependent, redundant, dynamic, cybernetic, synergistic, and creative (Reiser \& Dempsey, 2012).

Social Cognitive Theory according to (Schunk, 2012), suggests several assumptions that discuss the binding relationship between humans, behavior and environment in the learning process. The learning process will occur through direct practice or observation and role models.

Social teaching is a learning process that studies social behavior and emphasizes social interaction to achieve academic learning. The main role of educators is to prepare and develop democratic behavior at the individual and social level so that productive social life is achieved. This social teaching process argues that efforts carried out together can produce a happy quality of life and prevent adverse social conflicts (Joyce, Weil, \& Calhoun, 2009).

Social cognitive theory confirms that the learning process is largely determined through the process of observation and modeling. In the learning process, Students must have attention, so that they can pay attention and what they observe, then so that what they learn can be remembered, there needs to be retention and the results observed, this retention process is influenced by the verbal abilities of individuals. Then after students save the modeling process the lecturer must help students to be able to reproduce what they learn through behavior, and so that changes in behavior can be done again, it requires a reward or motivation from outside to encourage for students to make changes to their behavior repeatedly. The method that can be used to create this observational learning process with demonstrations, films, television shows, displays a real event (Schunk, 2012)

Facts have shown that students only respond to learning that can be actively understood. Then it needs a learning method that can explore students' perceptions. Link learning with important tasks and knowledge they have. This activity can be done during ore-learning, as a preliminary step to bridge the attention of participants in the learning process. Another way to help students is to use strategic teaching (Gagne \& Briggs, 1974)

Teaching that helps construct the meaning and knowledge previously possessed, with the material being studied. The way is by making summaries and self questions. Summarizing aims to help capture the subject matter of learning, distinguish important and not important ideas, and synthesize the main ideas. The process will enrich the understanding of the material that has been learned. While self-questioning is a cognition strategy to check the extent of understanding and mastery of material from students (Gredler, 2011)

This constructionist learning process is very good for learning in society that is inseparable from the social context. The learning method used to facilitate it is active learning, group learning, reflection and learning while working/practicing. Because the essence of the student will learn through this active involvement, through learning while working participants will build or be able to create new knowledge with the knowledge they already have. Even participants will think about

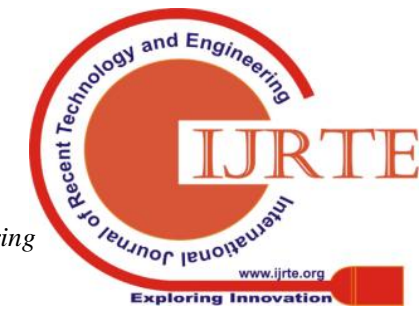


how to implement their new knowledge (Jamaris, 2013).

\section{METHODS AND PROCEDURAL}

This study used a qualitative approach with a development method known as R \& D (Research and Development) developed by Borg and Gall. This research will only be carried out until the product trial, with formative evaluation. Formative evaluation results were carried out by experts, students, and lecturers conducted, using one-to-one processes, Small groups, and Field Trials. Data was collected through interviews, questionnaires, and field observations. Data analysis using descriptive methods.

Procedure the steps to develop a midwifery learning model with a spiritual approach are as follows; 1) Identification of learning objectives, 2) conducting learning analysis, 3) identifying initial behavior and characteristics of students, 4) writing specific learning goals (ICT), 5) developing learning outcomes assessment tools, 6) developing learning strategies, 7) Developing learning materials , 8) Develop evaluation tools, 9) Formative Evaluation.

\section{A. Sample}

The expert team is carried out by the material experts, education technologists, graphic experts, media and languages. The evaluation of the expert team was carried out using questionnaires and interviews so that responses, inputs, and suggestions could be set out to improve the product. Informants for one-to-one leaner number of 3 people, small group 8 people and Field Trial 29 people. This research was conducted at the Ministry of Health III Polytechnic in the Jakarta Midwifery Study Program, Jan. Jasmine 2 N0. 15 Antiwar Pondok Melati, Bekasi 17415 West Java,

\section{RESULTS AND FINDINGS}

Before the developer conducts research, formative instruments are first validated by experts, with the following procedure; The selection of experts to validate formative instruments takes into account expertise about educational technology and learning evaluation. Formative evaluation instruments are submitted to experts to be validated and examined by a validation. Then each formative evaluation instrument item is analyzed based on the results of expert validation, to determine whether to use without repairs, used with repairs, or not used. From this stage, the instrument is ready to be tested. Validation of evaluation instruments by experts produces the following

\section{A. Draft Model 1}

The development model begins with the design of a conceptual model for developing the design of spiritual midwifery learning. Learning Neuroscience shows extraordinary human strength because using the human brain can be an unexpected person, even the brain can affect all human activities and behavior in this life. Social learning reciprocal relationships between humans this theory shows humans learn from the process of interaction between family and midwives, the duties and involvement of spiritual midwives.

Learning theories researchers linked to the demands of midwife competency standards and midwifery concepts, the researchers developed a learning model with a spiritual approach 1) Spiritual midwifery; spiritual understanding, spiritual values, service with heart/spiritual, and spiritual energy. 2) ways of thinking/mindset; brain anatomy, subconscious power, physical reaction, mind power and belief in body strength, 3) Childbirth assistance, attendance support with comfort and encouragement, 4) Intra and Interpersonal communication, empowering conscience, mother to fetus communication, and analysis of childbirth experience in case studies, 5) complementary and alternative therapies for pain relief during labor, the nature of pain in labor, conventional approaches, alternative approaches and alternative methods of practice eliminating labor pain, 6) maintaining normal relationships, labor physiology, internal physiological law labor, the cycle of labor, how to deal with normalizing labor and identifying childbirth experiences from several successful stories.

The feasibility of the model is done through expert review used in this study involving several experts, each expert in their field consists of; midwifery material experts, educational technology, language and media also involved lecturers in midwifery concept material.

The feasibility of the model is carried out after being validated by a team of experts in their field, the next process is to conduct an expert review after the field trial is carried out.

\section{B. Draft Model 2}

Based on the input and revision of the expert review, the spiritual midwifery learning model has been perfected. The result of this improvement into the spiritual midwifery learning model is with the following stages:

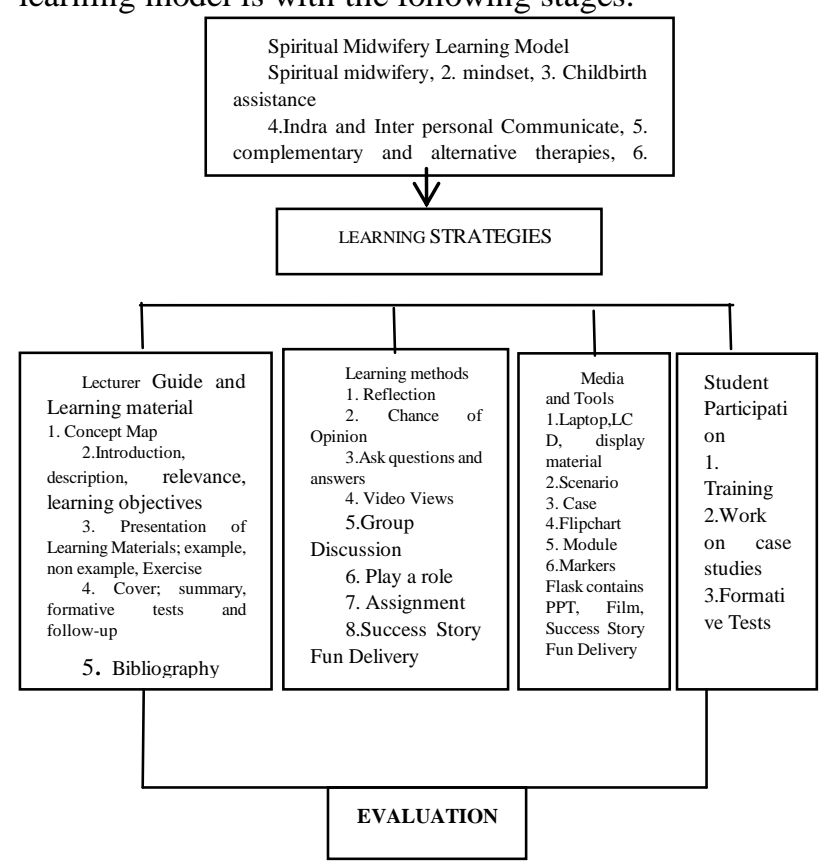

Fig 1: Spiritual Midwifery Learning Model 


\section{How to Develop a Learning Model with a Spiritual Method to Midwifery Diploma IV Students}

\section{Draft Model 3}

The process of testing done in three stages, consisting of 1)Trial individual (one to one leaner), 2) Trial group (small group), 3) Trial major groups (field trial). The three stages of the model trial were conducted to see THE effectiveness of the use of the model developed.

The response of students to assess the suitability of the Model and student attitudes towards this Model is an average value of 4.25 or $85 \%$. The material provided is very relevant in revolutionary holistic and physiological midwifery care, because midwives must also know that there are so many benefits of brain function, hormones, conscious mind, and subconscious especially for midwifery students. The material provided is very useful and very knowledgeable, but not only for midwives and for the community, women can read it apply during pregnancy, childbirth and childbirth, the material is not too difficult and can be reached by anyone especially with case studies / some childbirth experiences.

\section{Draft Model 4}

Results obtained from small groups (Small Group), include five indicators of the effectiveness of the developed model consisting of; 1) attractiveness of learning material, 2) duration / time of learning, 3) level of difficulty of the material, 4) suitability of use of illustrations, 5) suitability of tests with TPK. The response of students to the trial of indicators can be described as follows. Overall the quality of student responses to small group trials on the acceptance and usefulness of the developed model can be concluded that the midwifery learning approach of the spiritual approach for midwifery D IV students is feasible and can be continued in group trials field.

The results obtained from a large group (Field Trial), covering three indicators of effectiveness The model developed consists of; 1) attractiveness of learning material, 2) conformity of material with science and technology, 3) product feasibility and 4) assessment of the learning process through observation.

It can be concluded that the design products of the spiritual midwifery learning system developed are feasible and can be used (recording comments by some students). Test description of this field has reflected the characteristics of the end user of the product being developed.

Ratings learning process is done through observation of learning activities begin, the introduction is at an average level 4 , the presentation of 3.71 , student behavior, 3.66 and cover with an average of 4 , so the results of the learning process assessment are at an average level of 3.84 which means that it is in accordance with what was planned.

Level of effectiveness of the individual trial model and small group trials, the level of effectiveness of the results of field trials can also be seen from the quality of the results of the formative initial test and the final test showing that this model is effective done by students for trial results the field numbered 29 people whose results from the average pretest were 45.62 and the results of the average test post were 70.76 , this average number is still in good value with the presentation of the increase in grades 25.14 . The results of the pretest and the test post are illustrated in figure 2;

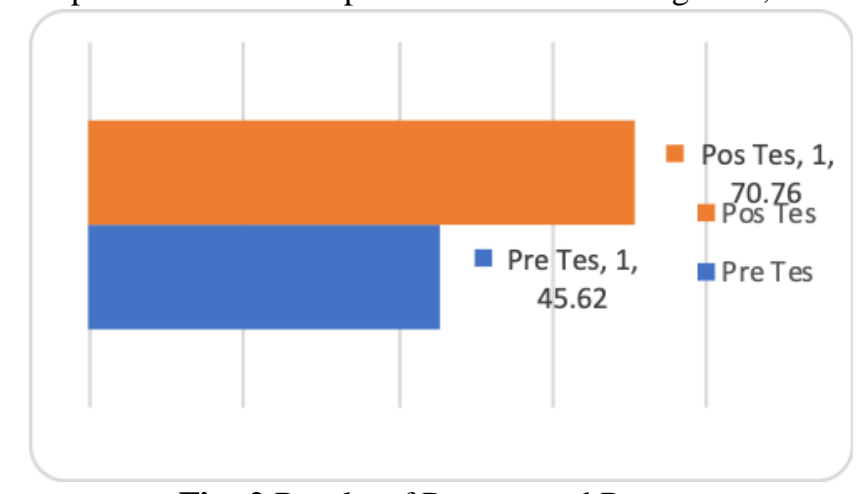

Fig: 2 Results of Pretests and Postest

\section{DISCUSSION}

This section will present a discussion of the results of the expert team's assessment and the results of the field trials. The discussion of development data will be presented in three parts, namely 1) attractiveness of learning material, 2) conformity of material with science and technology, 3) product feasibility, 4) weaknesses and 5) product excellence.

\section{A. Learning Materials}

Results of responses from large group trials on the attractiveness of spiritual midwifery learning material are very interesting illustrated from the average level of 4.48, or $89.65 \%$, according to students is very interesting and systematic, not too many new things, giving examples facilitates understanding, the glossary is very helpful. This learning material is very feasible to use as a learning resource because it can improve the competence of midwives.

Supported by expert opinion on the material truths of the concepts described are by the scope of the disciplines of midwives and can be accounted for from the relevant knowledge because this has used relevant sources. Based on the results of validation of conformity with competencies in the Model is very feasible with the average criteria of 5 or $100 \%$ meaning that according to experts the material can already be used as learning materials in the concept of midwifery.

By social cognitive theory (Schunk, 2012) says that human beings essentially learn and process interactions, behaviors, examples, and models that they experience directly in their environment. Information obtained based on observations, listening to the experiences of others, and experiences of doing it themselves give rise to new views of individuals. This can shape knowledge, skills and performance improvements, as planned learning outcomes.

\section{B. Conformity Of Material With Science And Technology}

Response from the trial is that students declare new learning about spiritual midwifery, the material is sequential and by evidence-based midwifery. In any matter the language is very interesting and complete with related research, drawn from the level of the average reached $4: 58$ or

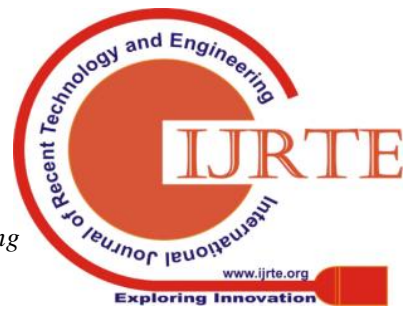


$91.72 \%$, is highly relevant to the competence of midwives

Accordance Expert opinions matter obstetrics spiritual been following the development in disciplines that are cutting-edge for the obstetrics edge here the world of obstetrics is up to date not High technology but High Touch, so it will be deeper spiritual touch where participants have begun to understand the values of those held by clients and families and he has also begun to appreciate the power that influences labor in psycho-spiritual.

Retained learning experience, both might involve the search for meaning and purpose, transcendence, interconnectedness and values. In this case, religious involvement is similar to spirituality. By Brian J knowledge of religious and spiritual beliefs, experience, and behavior has accumulated. With the approach of the new millennium, popular and scientific interests in religion and spirituality continue to develop (Mueller, Plevak, \& Rummans, 2001).

Referring to Schunk opinion about reflection in action, th at reflection is a process of thinking about the actions that have been taken will produce new knowledge, then it will produce new actions. Whereas socially, reflection is an effort to see the social influence on the actions taken, because in essence experience will never be separated from social conditions and social pressures that occur at that time. So if we think about practice then we think about situations that occur during practice.

Supported by constructivism learning directed to build new knowledge and change old beliefs, by learning and the power of thinking and experience of participants. It is a way of learning that focuses on maximizing student understanding. The learning process emphasizes the active role of students in understanding the meaning of information learned from the context of their environment.

The process of cognitive learning according to Vygosty emphasizes that efforts to solve problems are a high level of cognitive learning because participants are required to identify actual problems that often occur, and are required to think about efforts to solve them. This exercise facilitates participants' ability to think critically, quickly and logically The model should have high adaptability to the development of science and technology. Adaptive said if the model can adjust the development of science and technology and is flexible/flexible to use in various hardware devices.

\section{Product Feasibility}

The product feasibility indicator developed received a good response reaching 4.3 or $86.01 \%$, according to the trial students starting from the model display, learning objectives, media and learning methods, description of learning materials, summaries, exercises, and very formative tests worthy. The use of illustrations in the form of photos, videos, success has already had a good composition so that it provides an attraction and is motivated to read it. The contents of the material provided are very relevant in revolutionary midwifery care that is holistic and physiologically easy to implement because there are concrete examples,

Supported by expert opinion This spiritual midwifery is needed by users and students to be very well rated by experts, namely achieving average criteria 5 or $100 \%$. This means that spiritual midwifery material is very much needed because there is still a lack of learning materials that can be applied and this learning model can increase the confidence of midwives in maintaining natural childbirth.

Furthermore, the use of film media and is carried out to strengthen the cognitive learning process, optimize the power of audio, visually as the strength of the participants. Creating pleasant conditions, to optimize the power of the subconscious mind that can optimize the right brain function in understanding and interpreting the material being studied. To keep the situation pleasant, comfortable, so that concentration and motivation to learn are maintained, then the music accompanies the stages of the learning process.

Through a variety of learning strategies that can affect human behavior, environmental variables, and several personal factors and individuals in cognition such as efficacy and greatly affect the success of a person in learning. This theory shows that human beings essentially learn and process interactions, behavior, examples, and models, which they experience directly in their environment. Information obtained based on observations, listening to other people's experiences, and the experience of doing it themselves raises new beliefs and views for individuals. This can shape knowledge, skills and performance improvements, as a result of the planned learning process.

Learning Reflections pioneered by Colb, developed by Jarvis, are very useful to help the learning process become deeper and more useful because the knowledge gained as new information becomes functional when it is associated with experiences that have been experienced. The internalization process occurs, the process of understanding new things is faster. The process can generate strength to do something new, according to the roles and responsibilities, which will play or do.

The process of cognitive learning emphasizes that efforts to solve problems are a high level of cognitive learning because participants are required to identify actual problems that often occur, and are required to think about efforts to solve them. This exercise facilitates participants' ability to think critically, quickly and logically. The activity is expected to lead to readiness to think quickly when facing a critical phase in pregnancy, childbirth or newborns. Students can choose the appropriate alternative solutions.

Neuroscience development shows that the right brainpower in capturing a memory and creating concentration can help the process of understanding in learning. Changing the mindset and habits that have been held by individuals, so that the effective learning process of the situation and the learning process is created comfortable and enjoyable.

The process of the spirituality of teaching is made possible by increasing the understanding of students from the inner world based on perception, mind, and emotion, as suggested by London at. Al. As the teaching process recognizes dialog, reflective, creative,

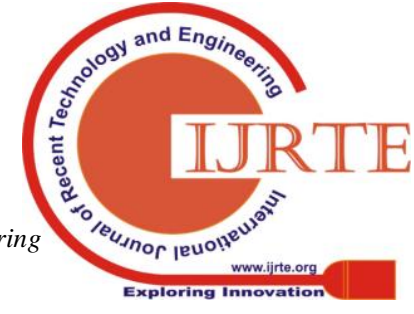




\section{How to Develop a Learning Model with a Spiritual Method to Midwifery Diploma IV Students}

exploitative, interactive, cooperative approaches to learning; openness practice; attention to experience; and sensitivity to the world.

Teaching is like maintaining the spiritual nature of students. He tried to ensure meaningful and significant learning, as observed by Rogers. This extends institutional boundaries and reaches outside the school as the only or main place where education takes place. Thus, teaching spirituality is not by instructional activities. On the contrary, it is a journey where new learning, experience, skills, attitudes, and responses are made, and where lecturers are also students, and students are also lecturers. They both are co-creators of their inner reality, and friends on the spiritual.

To implement the principles mentioned above, the learning methods in each session were created involving participatory students, reflecting the experiences of the students, activating the right and left brains using media, films, interesting material, learning accompanied by music, showing some of the client's successes

\section{Product Feasibility}

The product feasibility indicator developed received a good response reaching 4.3 or $86.01 \%$, according to the trial students starting from the model display, learning objectives, media and learning methods, description of learning materials, summaries, exercises, and very formative tests worthy. The use of illustrations in the form of photos, videos, success has already had a good composition so that it provides an attraction and is motivated to read it. The contents of the material provided are very relevant in revolutionary midwifery care that is holistic and physiologically easy to implement, because there are concrete examples,

Supported by expert opinion This spiritual midwifery is needed by users and students to be very well rated by experts, namely achieving average criteria 5 or $100 \%$. This means that spiritual midwifery material is very much needed because there is still a lack of learning materials that can be applied and this learning model can increase the confidence of midwives in maintaining natural childbirth.

Furthermore, the use of film media and and is carried out in order to strengthen the cognitive learning process, optimize the power of audio, visually as the strength of the participants. Creating pleasant conditions, to optimize the power of the subconscious mind that is able to optimize right brain function in understanding and interpreting the material being studied. To keep the situation pleasant, comfortable, so that concentration and motivation to learn are maintained, then the music accompanies the stages of the learning process.

Through a variety of learning strategies that can affect human behavior, environmental variables, and several personal factors and individuals in cognition such as efficacy and greatly affect the success of a person in learning. This theory shows that human beings essentially learn and process interactions, behavior, examples, and models, which they experience directly in their environment. Information obtained based on observations, listening to other people's experiences, and the experience of doing it themselves, raises new beliefs and views for individuals. This can shape knowledge, skills and performance improvements, as a result of the planned learning process.

Learning Reflections pioneered by Colb, developed by Jarvis, are very useful to help the learning process become deeper and more useful, because the knowledge gained as new information becomes functional when it is associated with experiences that have been experienced. The internalization process occurs, the process of understanding new things is faster. The process can generate strength to do something new, according to the roles and responsibilities, which it will play or do.

The process of cognitive learning emphasizes that efforts to solve problems are a high level of cognitive learning, because participants are required to identify actual problems that often occur, and are required to think about efforts to solve them. This exercise facilitates participants' ability to think critically, quickly and logically. The activity is expected to lead to readiness to think quickly, when facing a critical phase in pregnancy, childbirth or newborns. Students are able to choose the appropriate alternative solutions.

Neuroscience development shows that the right brain power in capturing memory and creating concentration can help the process of understanding in learning. Changing the mind set and habits that have been held by individuals, so that the effective learning process of the situation and the learning process is created comfortable and enjoyable.

The process of spirituality of teaching is made possible by increasing the understanding of students from the inner world based on perception, mind, and emotion, as suggested by London at. Al. As the teaching process recognizes dialog, reflective, creative, exploitative, interactive, cooperative approaches to learning; openness practice; attention to experience; and sensitivity to the world.

Teaching is like maintaining the spiritual nature of students. He tried to ensure meaningful and significant learning, as observed by Rogers. This extends institutional boundaries and reaches outside the school as the only or main place where education takes place. Thus, teaching spirituality is not in accordance with instructional activities. On the contrary, it is a journey where new learning, experience, skills, attitudes, and responses are made, and where lecturers are also students, and students are also lecturers. They both are co-creators of their inner reality, and friends on the spiritual.

To implement the principles mentioned above, the learning methods in each session were created involving participatory students, reflecting the experiences of the students, activating the right and left brains using media, films, interesting material, learning accompanied by music, showing some of the client's successes. in a pleasant labor process, it will stimulate the work of the right brain to activate the subconscious mind to capture the messages learned. Involving confident, social and problem-solving interactions, so that

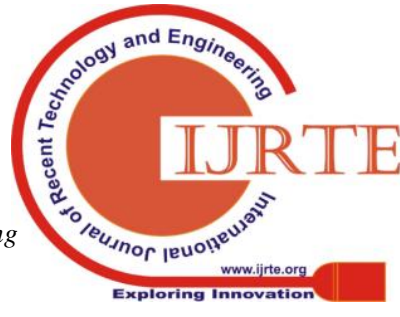


self-confidence, creativity, and the ability to make decisions to be trained, this will lead to student independence in setting priority needs.

This research develops the design of spiritual midwifery learning for midwifery concept courses and has made every effort to create applied and enjoyable learning supported by theories of Educational Technology and Midwifery Theory.

In this study, it proved to be feasible and effective to help facilitate students to apply concepts by the real and concrete world, but besides having the power of this research, it also has weaknesses.

\section{Conclusion}

From the whole process of research on the design of the spiritual midwifery learning system model in midwifery concept courses for midwifery DIV students, conclusions can be drawn as follows; 1. The concept of midwifery is still theoretically based on theories, there are no guidelines for how to apply it to various methods, media and evaluation systems, and examples of how to apply it. The answers to the questionnaire and observation found that the ability of lecturers to design good and effective learning systems was not optimal.

2. The process of developing a spiritual midwifery learning model is carried out through several stages; 1) identification of needs, including preliminary research, determination of learning objectives, identification of student characteristics and analysis of learning. 2) Designing and developing models includes formulating specific objectives, developing instruments, developing learning strategies, developing teaching materials and developing evaluation tools. 3) evaluation and revision includes evaluation of experts, evaluation of one student, small group trials, and field trials and revisions.

3. Product effectiveness can be seen starting from expert judgment, testing one student, small group trials, and field trials, finding the fact that the spiritual midwifery learning model is able to facilitate and motivate students. The spiritual midwifery design model is feasible and can be used.

\section{REFERENCES}

1. Baldacchino, D. R. (2008). Teaching on the spiritual dimension in care to undergraduate nursing students: The content and teaching methods. Nurse education today, 28(5), 550-562.

2. Branch, K. L. G. a. R. M. (2002). Survey of Instructional Development Models. New York: Syracuse University.

3. Crowther, S., \& Hall, J. (2015). Spirituality and spiritual care in and around childbirth. Women and Birth, 28(2), 173-178.
4. Gagne, R. M., \& Briggs, L. J. (1974). Principles of instructional design: Holt, Rinehart \& Winston.

5. Gredler, M. E. (2011). Learning And Instruction Teori dan Aplikasi terjemahan Triwidodo. Jakarta: Kencana Prenada Media.

6. Hall, J. (2016). Facilitating learning of spirituality in midwifery. Spiritual Care, 5(2), 81-88.

7. Jamaris, M. (2013). Orientasi baru dalam psikologi pendidikan. Bogor: Ghalia Indonesia.

8. Josephine, A., Donia, R., \& Baldacchino, L. C. (2014). Nurses' and midwives' acquisition of competency in spiritual care: A focus on education. Nurse Educ Today.

9. Joyce, B., Weil, M., \& Calhoun, E. (2009). Models of Teaching, Upper Seddle River New Jersey: Pearson Education, Inc.

10. Kostak, M. A., \& Celikkalp, U. (2016). Nurses and Midwives Opinions about Spirituality and Spiritual Care. International Journal of Caring Sciences, 9(3).

11. Midwives, R., C. o. (Mey 2004). [Press release]

12. Molenda, M., \& Januszewski, A. (2008). Educational technology: A definition with commentary. Association for Educational Communications and Technology (AECT).

13. Moloney, S., \& Gair, S. (2015). Empathy and spiritual care in midwifery practice: Contributing to women's enhanced birth experiences. Women and Birth, 28(4), 323-328.

14. Mueller, P. S., Plevak, D. J., \& Rummans, T. A. (2001). Religious involvement, spirituality, and medicine: implications for clinical practice. Paper presented at the Mayo clinic proceedings.

15. Reigeluth, C. M. (1999). A new paradigm of instructional theory: L. Erlbaum.

16. Reiser, R. A., \& Dempsey, J. V. (2012). Trends and issues in instructional design and technology: Pearson Boston, MA.

17. Richey, R. C., \& Klein, J. D. (2014). Design and development research: Methods, strategies, and issues: Routledge.

18. Ross, L., McSherry, W., Giske, T., van Leeuwen, R., Schep-Akkerman A., Koslander, T., . . . Jarvis, P. (2018). Nursing and midwifery students' perceptions of spirituality, spiritual care, and spiritual care competency: A prospective, longitudinal, correlational European study. Nurse education today, 67, 64-71.

19. Schunk, D. H. (2012). Learning theories an educational perspective sixth edition: Pearson.

20. Walter Dick, L. C., and James O.Carry. (2015). Tre Systematic Design of Instruction Eighth Edition. Baston: Library of Congress Cataloging in-Publication Data.

\section{Author's Profile.}

I am Hasnerita from Post Graduated Departmen of Educational Technology Universitas Negeri Jakarta. Rawamangun muka street, Rawamangun Pulogadung, East Jakarta 13220, Indonesia., Hanerita_tp. My area of interest is education, research and development.

I am Suyitno Muslim a Profesor at Universitas Negeri Jakarta. Rawamangun Muka street, Rawamangun Pulogadung, East Jakarta 13220, Indonesia. My area of interest is education, research and development.

I am Atwi Suparman a Profesor at Universitas Terbuka Jakarta. Jalan Cabe Raya, Pondok Cabe Pamulang, Tangerang Selatan 15418, Banten Indonesia. My area of interest is education, research and development. 